\title{
Carbon Capture and Storage and Carbon Capture and Utilization: What Do They Offer to Indonesia?
}

\author{
Didi Adisaputro ${ }^{1,2 *}$ and Bastian Saputra ${ }^{1}$ \\ ${ }^{1}$ Department of Chemical and Biological Engineering, University of Sheffield, Sheffield, UK, ${ }^{2}$ Department of Energy Security, \\ Indonesian Defence University, Bogor, Indonesia
}

Keywords: $\mathrm{CO}_{2}$ emission, energy, carbon capture and storage, $\mathrm{CCU}$, Indonesia

\section{INTRODUCTION}

Indonesia is a developing country with abundance resource of fossil fuel in the world, and this fossil fuel will remain as the main source of energy over the next few decades. However, the Indonesian Government has committed to reducing greenhouse gas emissions from fossil fuel consumption as an effort to mitigate climate change. In view of this, two possible energy scenarios are envisioned to honor this commitment: "business as usual" (BaU) and the National Energy Policy (NEP) scenario (National Energy Council, 2014). The NEP scenario reduces $\mathrm{CO}_{2}$ emissions by up to $26 \%$ through

OPEN ACCESS

Edited by:

Yuhan Sun,

Shanghai Advanced Research Institute, China

Reviewed by: Mingquan Wang, Shanghai Advanced Research Institute, China

*Correspondence: Didi Adisaputro didiadisaputro@gmail.com

Specialty section: This article was submitted to Carbon Capture, Storage, and Utilization, a section of the journal Frontiers in Energy Research

Received: 28 October 2016 Accepted: 13 March 2017 Published: 30 March 2017

Citation: Adisaputro D and Saputra B (2017) Carbon Capture and Storage and Carbon Capture and Utilization: What Do They Offer to Indonesia?

Front. Energy Res. 5:6. doi: 10.3389/fenrg.2017.00006 an improved energy mix, less reliance on carbon-based fuels, and the deployment of renewable energy sources from 2020 to 2050. However, these actions are considered insufficient to further reduce the $\mathrm{CO}_{2}$ emission target, leading to an initiative to implement carbon capture and storage (CCS) technology.

Although Indonesia is a developing country, it has a mature manufacturing industry, which means that carbon-capture utilization $(\mathrm{CCU})$ technology, which converts $\mathrm{CO}_{2}$ into useful products and intermediates, could provide an additional method to complement CCS technology and help decouple economic growth from excessive $\mathrm{CO}_{2}$ emission (Styring et al., 2014).

This report reviews how CCS and CCU are applied in Indonesia, particularly in relation to the energy sector. In addition, $\mathrm{CO}_{2}$ emissions from future fossil fuel consumption are predicted together with the amount of $\mathrm{CO}_{2}$ emitted that is suitable for CCS. The barriers hindering the application of CCS are also reviewed together with the alternatives to CCU technology. Because of some drawbacks in the development of CCS, the potential of CCU deployment is assessed, leading to several recommendations. Finally, we discuss what the application of both CCS and CCU can offer Indonesia.

\section{CARBON CAPTURE AND STORAGE}

Implementing CCS involves the application of $\mathrm{CO}_{2}$ capture technology, transportation and injection into storage facilities, and monitoring (ADB, 2013). The Global CCS Institute (2016) reports that, in 2016, most ongoing CCS projects worldwide are applied in oil and gas, power, and the industrial sector. Some examples include the Uthmaniyah $\mathrm{CO}_{2}$-enhanced oil recovery (EOR) project in Saudi Arabia and the Boundary Dam Power Plant CCS Project in Canada.

The Indonesian Government has also considered CCS as a national strategy, as demonstrated by the existing CCS pilot project in Merbau Gas Gathering Station. The captured $\mathrm{CO}_{2}$ is injected into the depleted oil and gas reservoir surrounding the point of source. This project will store $50-100$ t of $\mathrm{CO}_{2}$ per day for several months starting in 2016 and will be shut-in for assessment in 2018 [LEMIGAS (R\&D Centre for Oil and Gas Technology), 2012]. 
However, some barriers remain that hinder the deployment of CCS. The retrofitting of $\mathrm{CO}_{2}$ capture technology to power plants often confronts technical barriers that increase the cost of producing electricity. Other technical barriers come from site selection, storage capacity, transportation, and the degree of confidence in terms of geological modeling and monitoring. Social barriers may also arise because of the safety issues connected with leakage, long-term liability, and public acceptance (Styring et al., 2011).

\section{CARBON CAPTURE AND UTILIZATION}

Indonesia has initiated several research programs targeting climate change and $\mathrm{CO}_{2}$ reduction. However, most of these programs examine only the role of natural $\mathrm{CO}_{2}$ sequestration rather than $\mathrm{CO}_{2}$ conversion into commercial products. The idea of CCU technology is to convert $\mathrm{CO}_{2}$ into various valuable products. Aresta (2010) has researched $\mathrm{CO}_{2}$ synthesis into carboxylates, carbonates, carbamates, isocyanates, and polymeric materials that have been examined for use in electrochemistry and photo electrochemistry. $\mathrm{CO}_{2}$ and its co-reactant can be activated and further transformed into a useful chemical either by creating high-energy salts or by using catalysts (Styring et al., 2014).

However, other than for producing urea, the use of CCU on an industrial scale remains insignificant, especially for direct capture from flue gas. This paper considers the CCU concept only in conjunction with the conversion. Thus, $\mathrm{CO}_{2}$ use other than for conversion, such as the use of $\mathrm{CO}_{2}$ as a solvent, a working fluid for heat transfer, is not considered herein.

Carbon capture and utilization might also bring significant benefits to Indonesia because the wide-ranging products have increasing market potential, which is of interest because of Indonesia's large population coupled with its economic growth. The population of Indonesia is currently around 257 million and is predicted to rise to 285 million in 2030 and 322 million in 2050 (United Nations, 2015).

\section{CCS AND CARBON CAPTURE AND UTILIZATION FOR INDONESIA}

Figure 1 shows the trend of fossil fuel consumption and the related $\mathrm{CO}_{2}$ emission in Indonesia. Fossil fuel consumption has increased from 53.4 Mtoe in 1990 to 154.93 Mtoe in 2013, when the oil share was around $50-60 \%$. The NEP scenario would reduce the oil share to $25-30 \%$, but the overall fossil fuel consumption should increase to 690 Mtoe in 2050. This increase in fossil fuel consumption will be accompanied by arise in $\mathrm{CO}_{2}$ emission. In 1990, $\mathrm{CO}_{2}$ emission was 133.9 Mtoe, which increased to 133.9 Mtoe in 2013. In 2030 and 2050, it is predicted to reach 1000.6 and 2065.98 Mtoe, respectively.

Although the NEP scenario aims to increase the share of renewable energy sources, it will be insufficient to achieve an overall $26 \%$ reduction in $\mathrm{CO}_{2}$ emission in 2020. As a result, CCS must be applied as a tool to significantly mitigate $\mathrm{CO}_{2}$ emission, particularly $\mathrm{CO}_{2}$ emission from the oil and gas, power, and industrial sectors.
In 2012, through LEMIGAS, the Indonesian Government estimates a storage capacity of 640 Mtoe of $\mathrm{CO}_{2}$ in depleted oil and gas fields, most of which are in Kutai, Tarakan, and the South Sumatra region. Considering the level of $\mathrm{CO}_{2}$ emission given in Figure 1, this $\mathrm{CO}_{2}$ storage capacity will not cover the predicted $\mathrm{CO}_{2}$ emissions from fossil fuel in 2030 or 2050 . Therefore, CCS might be more feasible if it focuses on the existing power plants and oil and gas facilities, particularly for locations close to the potential $\mathrm{CO}_{2}$ storage sites.

Currently, the most attractive option for CCS in Indonesia is $\mathrm{CO}_{2}$ storage in conjunction with EORs, because oil production has the potential to generate additional revenue that can offset the cost of CCS (Syahrial et al., 2010). However, for long-term CCS, this option is not expected to achieve the requisite $\mathrm{CO}_{2}$ reduction target because, when consumed, oil produced from EOR releases $\mathrm{CO}_{2}$. Furthermore, deploying CCS in the power sector may not only mitigate $\mathrm{CO}_{2}$ emissions but may also speed up industrialization by increasing the number of new power plants to achieve the national electrification target. The new construction of " $\mathrm{CO}_{2}$ capture ready" power plants may avoid the retrofit cost of $\mathrm{CO}_{2}$ capture (Syahrial et al., 2010).

The predicted fossil fuel consumption, the amount of $\mathrm{CO}_{2}$ emission, and the future population growth in Indonesia should increase the effort to explore and deploy CCS. A promising first step has been taken by the government in the form of the $\mathrm{CO}_{2}$ Storage Mapping Program run by the Coordinating Committee for Geoscience Programs in East and Southeast Asia (CCOP), whose goal is to investigate potential $\mathrm{CO}_{2}$ storage sites.

\section{Carbon Capture and Utilization}

The three largest-scale $\mathrm{CO}_{2}$-derived products are urea with $\sim 157$ Mtoe worldwide, followed by salicylic acid and cyclic carbonate with, respectively, $\sim 90$ and $\sim 80$ thousand tonnes worldwide (Styring et al., 2014). Indonesia contributed almost $5 \%$ to the global urea production in 2015 and is predicted to increase its production over the coming decades. According to the Ministry of Industry of the Republic of Indonesia (2010), after the world recession of 2008, Indonesia experienced no economic instability. Instead, all economic sectors enjoyed growth during 2009, including manufacturing. The fertilizer and chemical sectors alone had stable growth, averaging about 5\% from 2005 to 2008. These industries are promising for spurring the development of CCU in Indonesia.

For CCU applications, significant energy is required to satisfy specific capturing and conversion technology. Therefore, the energy must come from an excess of renewable power rather than from fossil fuel, otherwise a net reduction in $\mathrm{CO}_{2}$ would be impossible (Styring et al., 2014). Thus, CCU is more applicable in the NEP scenario than in the BaU scenario because, in the former, sufficient energy for CCU comes from renewables and fossil fuel-based power plants are a source of $\mathrm{CO}_{2}$.

The transformation of energy systems involves significant investment and regulation from the related institutions. For regulations, the stabilization of political conditions in Indonesia is highly likely to affect the deployment of CCU technology. In addition to transforming energy systems, qualified human resources, mature carbon capture, and a transportation infrastructure 


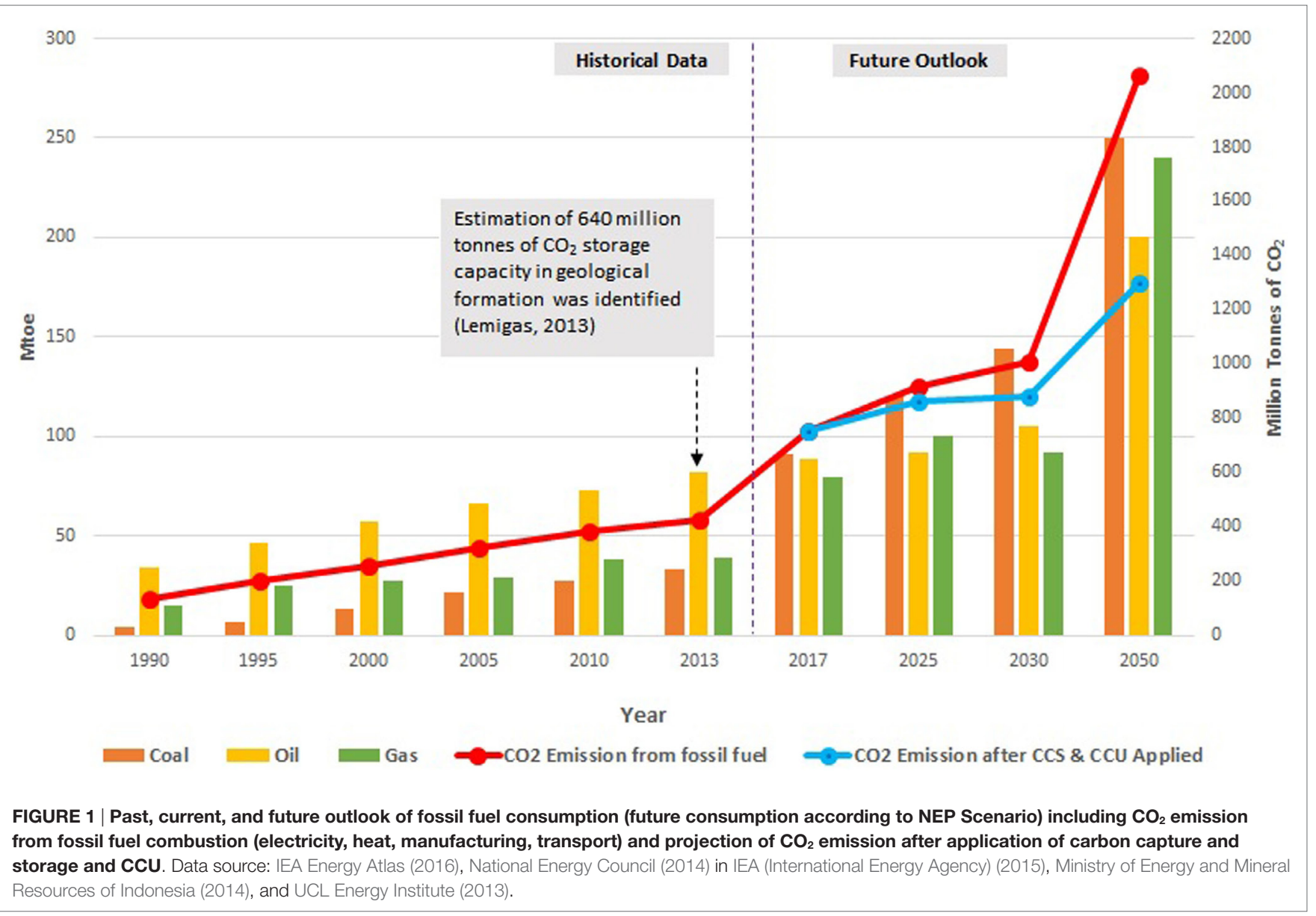

should also be available for $\mathrm{CO}_{2}$ conversion products to compete with conventional products. However, despite the advance of lowcost energy from renewables, market intervention by policy is still likely to be required to create market space for CCU products.

The Indonesian Government has proposed the National Industrial Development Master Plan (RIPIN) for the years 2015-2035. The CCU concept fits very well into this master plan because the plan regulates some important visions to develop green industries, including the use of eco-products, renewables, and low hazard substances (Presiden Republik Indonesia, 2015). RIPIN also mentions that the Indonesian Government might adopt a mature approach to green industry from another country. The European policy SCOT (a vision for smart $\mathrm{CO}_{2}$ transformation in Europe) is one recommended approach to support RIPIN. In SCOT, the initial plans for CCU include research into life-cycle assessment, policy frameworks, and carbon capture installations (Wilson et al., 2016). To successfully implement CCU, the technical and non-technical challenges of CCU must be addressed by Indonesia through sufficient funding and support from both the public and private sectors.

Figure 1 shows the prediction of how $\mathrm{CO}_{2}$ emission can change if the CCS and CCU are applied in the future. The prediction of $\mathrm{CO}_{2}$ emission would change significantly with the increase of emission reduction from $6 \%$ in 2025 to $37 \%$ in 2050 in case the CCS and CCU application has been applied. This estimation is based on the assumption of carbon capture technology will be applied to point $\mathrm{CO}_{2}$ sources (oil and gas facilities, power plants, and manufacturing) and considers the CCS capacity and efficiency (UCL Energy Institute, 2013) including the potential application of CCU in Indonesia.

\section{CONCLUSION}

Indonesia plans to reduce future $\mathrm{CO}_{2}$ emissions in spite of its energy scenario remaining reliant on fossil fuels. The potential of CCS in Indonesia would reduce $\mathrm{CO}_{2}$ emission from oil and gas, power plants, and industry. Because CCS alone is insufficient to attain the $\mathrm{CO}_{2}$ emission goals, $\mathrm{CCU}$ technology offers an alternative in which $\mathrm{CO}_{2}$ is put to use rather than simply sequestered. Carbon capture and utilization will be suitable if the Indonesian Government accepts the NEP scenario, which foresees a significant share of the energy mix coming from renewables. Carbon capture and utilization might be more attractive to Indonesia than CCS alone because the industrial products from $\mathrm{CO}_{2}$ have a significant potential market due to Indonesia's increasing population and concomitant economic growth. However, in Indonesia, the research and development of CCU is not well developed. Therefore, a framework within which CCU applications can be produced would lead to more efficient and sustainable use of Indonesia's resources and would result in an eco-competitive 
industry. In conclusion, applying CCS with CCU offers not only a reduction in $\mathrm{CO}_{2}$ emission but also the potential to decouple economic growth from $\mathrm{CO}_{2}$ emission.

\section{AUTHOR CONTRIBUTIONS}

DA and BS contributed equally to this work.

\section{REFERENCES}

ADB. (2013). Prospects for Carbon Capture and Storage in Southeast Asia. Philippines: Asian Development Bank.

Aresta, M. (2010). Carbon Dioxide as Chemical Feedstock. Weinheim: John Wiley \& Sons.

Global CCS Institute. (2016). Large Scale CCS Projects. Available at: https://www. globalccsinstitute.com/projects/large-scale-ccs-projects

IEA (International Energy Agency). (2015). Indonesia 2015. France: International Energy Agency.

IEA Energy Atlas. (2016). IEA Energy Atlas Statistics. Available at: http://www.iea. org/statistics/ieaenergyatlas/

LEMIGAS (R\&D Centre for Oil and Gas Technology). (2012). The Latest Status of Carbon Capture and Storage (CCS) in Indonesia. Republic of Indonesia: Ministry of Energy and Mineral Resources.

Ministry of Energy and Mineral Resources of Indonesia. (2014). Handbook of Energy and Economic Statistics of Indonesia. Indonesia: Pusdatin ESDM.

Ministry of Industry of the Republic of Indonesia. (2010). Industry for a Better Life. Jakarta: Kemenprin

National Energy Council. (2014). Indonesia Energy Outlook 2014. Republic of Indonesia: National Energy Council.

Presiden Republik Indonesia. (2015). Rencana Induk Pembangunan Industry Nasional (RIPIN) Tahun 2015-2035. Jakarta: Peraturan Pemerintah Republik Indonesia Nomor 14 tahun 2015.

Styring, P., Jansen, D., de Coninck, H., Reith, H., and Armstrong, K. (2011). Carbon Capture and Utilisation in the Green Economy. New York: Centre for Low Carbon Futures, 60.

\section{ACKNOWLEDGMENTS}

We would like to say thank you to our sponsor, this paper would not have been completed without support from LPDP (Indonesian Endowment Fund for Education). We are grateful to Dr. Grant Wilson for his supervision and insightful suggestion during the preparation of this paper.

Styring, P., Quadrelli, E. A., and Armstrong, K., editors. (2014). Carbon Dioxide Utilisation: Closing the Carbon Cycle. Elsevier.

Syahrial, B. E., Pasarai, U., and Iskandar, U. P. (2010). CCS potential in Indonesia. Understanding Carbon Capture and Storage (CCS) Potential in Indonesia. 33, 129-134.

UCL Energy Institute. (2013). Modelling of Global Energy Scenarios under $\mathrm{CO}_{2}$ Emissions Pathways with TIAM-UCL. London: UCL Energy Institute.

United Nations, Department of Economic and Social Affairs, Population Division. (2015). World Population Prospects: The 2015 Revision, Key Findings and Advance Tables. Working Paper No. ESA/P/WP.241. New York.

Wilson, G., Travaly, Y., Brun, T., Knipples, H., Armstrong, K., Styring, P., et al. (2016). A VISION for Smart $\mathrm{CO}_{2}$ Transformation in Europe (SCOT). Using CO ASA Resource. Seventh Framework Programme and European Union.

Conflict of Interest Statement: The authors declare that the research was conducted in the absence of any commercial or financial relationships that could be construed as a potential conflict of interest.

The reviewer MW and handling editor declared their shared affiliation, and the handling editor states that the process nevertheless met the standards of a fair and objective review.

Copyright (c) 2017 Adisaputro and Saputra. This is an open-access article distributed under the terms of the Creative Commons Attribution License (CC BY). The use, distribution or reproduction in other forums is permitted, provided the original author(s) or licensor are credited and that the original publication in this journal is cited, in accordance with accepted academic practice. No use, distribution or reproduction is permitted which does not comply with these terms. 